\title{
Optical and geometrical characteristics of cirrus clouds over a Southern European lidar station
}

\author{
E. Giannakaki ${ }^{1}$, D. S. Balis ${ }^{1}$, V. Amiridis ${ }^{2}$, and S. Kazadzis ${ }^{1}$ \\ ${ }^{1}$ Laboratory of Atmospheric Physics, Thessaloniki, Greece \\ ${ }^{2}$ Institute for Space Applications and Remote Sensing, Athens, Greece
}

Received: 4 May 2007 - Published in Atmos. Chem. Phys. Discuss.: 2 July 2007

Revised: 27 September 2007 - Accepted: 21 October 2007 - Published: 2 November 2007

\begin{abstract}
Optical and geometrical characteristics of cirrus clouds over Thessaloniki, Greece $\left(40.6^{\circ} \mathrm{N}, 22.9^{\circ} \mathrm{E}\right)$ have been determined from the analysis of lidar and radiosonde measurements performed during the period from 2000 to 2006. Cirrus clouds are generally observed in a mid-altitude region ranging from 8.6 to $13 \mathrm{~km}$, with mid-cloud temperatures in the range from $-65^{\circ}$ to $-38^{\circ} \mathrm{C}$. The cloud thickness generally ranges from 1 to $5 \mathrm{~km}$ and $38 \%$ of the cases studied have thickness between 2 and $3 \mathrm{~km}$. The retrieval of optical depth and lidar ratio of cirrus clouds is performed using three different methods, taking into account multiple scattering effect. The mean optical depth is found to be $0.31 \pm 0.24$ and the corresponding mean lidar ratio is $30 \pm 17 \mathrm{sr}$ following the scheme of Klett-Fernald method. Sub-visual, thin and opaque cirrus clouds are observed at 3\%,57\% and $40 \%$ of the measured cases, respectively. A comparison of the results obtained between the three methods shows good agreement. The multiple scattering errors of the measured effective extinction coefficients range from 20 to $60 \%$, depending on cloud optical depth. The temperature and thickness dependencies on optical properties have also been studied in detail. A maximum mid-cloud depth of $\sim 3.5 \mathrm{~km}$ is found at temperatures around $\sim-47.5^{\circ} \mathrm{C}$, while there is an indication that optical depth and mean extinction coefficient increases with increasing mid-cloud temperature. A correlation between optical depth and thickness was also found. However, no clear dependence of the lidar ratio values on the cloud temperature and thickness was found.
\end{abstract}

Correspondence to: E. Giannakaki

(egian@auth.gr)

\section{Introduction}

Cirrus clouds are made predominantly or wholly of ice (e.g. Lynch, 2002). These clouds affect the Earth's climate through two opposite effects; an infrared greenhouse effect and a solar albedo effect. The contribution of each effect depends strongly on cirrus optical properties (e.g. Zerefos et al., 2003). Thin cirrus clouds usually cause a positive radiative forcing at the top of the atmosphere, while thick cirrus clouds may produce cooling (Stephens and Webster, 1981; Fu and Liou, 1993; Fahey and Schumann, 1999). Significant uncertainties remain regarding the radiative and climate effect of cirrus clouds (IPCC, 2007). As cirrus clouds play a significant role in the radiative balance of the Earth's atmospheric system, a clear understanding of their properties at different geographical locations is highly essential for climate modeling studies.

Lidars are regarded as one of the leading techniques for remotely studying the characteristics and properties of cirrus clouds. Elastic backscatter and Raman lidars have been used to retrieve information on geometrical and optical properties of cirrus clouds, made through the application of methods that have been earlier demonstrated in the literature (e.g. Barrett and Ben-Dov, 1967; Viezee et al., 1969; Davis, 1969; Fernald et al. , 1972; Platt, 1973; Platt, 1979; Klett, 1981; Fernald, 1984; Grund and Eloranta, 1990; Ansmann et al., 1992). Some key microphysical parameters are the extinction coefficient, lidar ratio and depolarization ratio as well as the mid-altitude and the corresponding mid-cloud temperature of cirrus clouds (Sunilkumar and Parameswaran, 2005). The lidar and depolarazation ratios are considered to be of special importance since are related to microphysics properties of the ice crystals contained on cirrus clouds, while mid-altitude and mid-temperature play an important role in determining cloud radiative properties.

Published by Copernicus Publications on behalf of the European Geosciences Union. 
Comstock and Ackerman (2002) have studied the optical and geometrical properties of tropical cirrus clouds and found that high clouds occur on average $44 \%$ of the time. Sub-tropical cirrus clouds are present more frequently at austral summer than the austral winter as Cadet et al. (2003) have shown. The same study showed that $65 \%$ of the total cirrus observations are characterized as sub-visual, with an optical thickness of less than 0.03 . The threshold of 0.03 for optical thickness measured at the wavelength of $694 \mathrm{~nm}$ was first proposed by Sassen and Cho (1992) in order to separate cirrus clouds to visible and sub-visual. Goldfarb et al. (2001) found that $\sim 20 \%$ of total cirrus cloud occurrences are sub-visual for a mid-latitude lidar station in France. Reichardt (1999) has found that $70 \%$ of cirrus clouds were classified as subvisual or optically thin ice clouds (optical depths bellow 0.3). Sassen and Campbell (2001) have presented a mid-latitude climatology showing that optical depth of cirrus clouds is greater than 0.3 for $\sim 50 \%$ of detected cases. Seifert et al. (2007) have studied optical properties of tropical cirrus clouds and found $13 \%, 50 \%$ and $37 \%$ for subvisual, thin and opaque cirrus clouds, respectively. Many other studies have been performed and mainly focused on tropical cirrus clouds because of the high frequency of occurrence of sub-visual cirrus clouds and their significant influence on the Earth's atmospheric system (Comstock and Ackerman, 2002), as observed by SAGE (Stratospheric Aerosol and Gas Experiment) II (Wang et al., 1996; Wang et al., 1998).

The optical depth of clouds is a key parameter in radiative transfer computations and therefore considerable effort has been put in its retrieval. The evaluation of optical depth of cirrus clouds was done through the application of different methods which are already demonstrated in the literature. Most of these methods depend on the solution of the standard lidar equation (Barrett and Ben-Dov, 1967; Viezee et al., 1969; Davis, 1969; Fernald et al., 1972; Platt, 1973, 1979; Klett, 1981; Fernald, 1984; Ansmann et al., 1992; Elouragini and Flamant, 1996; Wandinger, 1998). A different technique to determine the optical depth of cirrus clouds from elastic lidar signal has also been developed. It is based on the comparison of the backscattering signals just below and above the cloud, assuming that the lidar signals correctly represented the scattering medium (Platt, 1973; Young, 1995; Elouragini and Flamant, 1996; Chen et al., 2002,). However, these methods have never been compared or validated against each other using long term lidar measurements.

In this study, after a brief description of the lidar system used, we present a short description of the data analysis methods, along with a typical analysis of a case study. The main objective of this part of the study is to evaluate the benefits of applying various methodologies to the lidar measurements as well as to investigate the limits of their applicability. Finally, a statistical analysis of mid-latitude cirrus clouds created from lidar data collected in Thessaloniki over the period 2000-2006 is presented and discussed.

\section{Instrumentation}

A two-wavelength combined elastic-backscatter Raman lidar located at the Laboratory of Atmospheric Physics (LAP), Thessaloniki, Greece $\left(40.6^{\circ} \mathrm{N}, 22.9^{\circ} \mathrm{E}\right)$ is used to perform continuous measurements of suspended aerosol particles and cirrus clouds. The system is based on the second and third harmonic frequency of a compact, pulsed Nd:YAG laser, which emits pulses of 300 and $120 \mathrm{~mJ}$ output energy at 532 and $355 \mathrm{~nm}$, respectively, at a $10 \mathrm{~Hz}$ repetition rate. The optical receiver is a $500 \mathrm{~mm}$ diameter telescope $(1 \mathrm{mrad}$ field of view). Three Hamamatsu 5600P-06 photomultipliers are used to detect the lidar signals at 532, 355 and $387 \mathrm{~nm}$. The acquisition system is based on a three-channel LICEL Transient Digitizer working in both the analogue (12bit ADC, $40 \mathrm{MHz})$ and the photon counting $(250 \mathrm{MHz})$ modes. The vertical resolution of the elastic raw signal at $355 \mathrm{~nm}$ is equal to $7.5 \mathrm{~m}$, while of the inelastic signal at $387 \mathrm{~nm}$ is equal to $15 \mathrm{~m}$. Several smoothing procedures are applied to the raw signals when retrieving the optical properties and are discussed in the next section. The LAP lidar is operated at a fixed-off zenith angle, pointing vertically.

The LAP lidar was successfully intercompared in the frame of the European Aerosol Research Lidar Network (EARLINET) systems, showing on the average an agreement of better than $5 \%$ for heights above $2 \mathrm{~km}$ in the backscatter coefficient (Matthias et al., 2004; Bockmann et al., 2004; Pappalardo et al., 2004). More technical and measurement details concerning the LAP lidar system can be found in the literature (Balis et al., 2003; Amiridis et al., 2005). Within the EARLINET project, coordinated lidar measurements are being performed at 22 lidar stations which are located at 12 European countries. The measurements began on May 2000 and three synchronous observations per week were performed from May 2000 to November 2002. Most of the EARLINET stations continued this schedule also after the year 2002.

In this study, we present lidar measurements performed over Thessaloniki, for cases when cirrus clouds were observed in the period 2000-2006. Fifteen cases of Raman (nighttime) measurements and thirty eight cases of daily measurements were found during the routine schedule of the measurements. For 49 of the total measurements (53), temperature vertical profile data from radiosondes were used to yield the temperature of the base and top of the cirrus cloud.

\section{Methodology}

In order to get reliable and quantitative results for the optical properties of cirrus clouds three different methods are briefly presented and used in this study.

In our study, only clouds with mid-cloud temperature below $-38^{\circ} \mathrm{C}$ are considered in order to avoid a possible impact of water clouds to our measurements. This threshold 
corresponds to cirrus clouds with mid-cloud altitude above $8600 \mathrm{~m}$. It is important to state that even in this case, some cloud systems may still be mixed-phase clouds. In case of different cirrus layers we interpreted them as different ice clouds only when they were separated by $500 \mathrm{~m}$.

One main aspect of all methods is the accurate determination of the cirrus cloud boundaries. This aspect is of major importance not only for the correct application of methods applied here, but also for the precise calculation of the geometrical properties of cirrus clouds. The height of base and top of the cirrus clouds are calculated by the lidar signals.

The cloud-base altitude is defined as that point at which there is an increase in the system's signal level that equals two times the standard deviation of the background. To avoid the impact of noise, we require that the signal continues to increase for at least 5 successive height intervals. Cloud top can be determined by calculating the standard deviation of noise above cloud top, and moving downward in altitude from maximum range. This method was proposed by Platt et al. (1994). Accordingly, the mid-cloud height is defined as the geometric center of the cirrus cloud.

3.1 Methodology for the retrieval of the cirrus optical characteristics

\subsubsection{Klett-Fernald method}

Most of the methods that have been developed to retrieve the optical properties of cirrus clouds depend on the solution of the standard lidar equation. Generally, the two unknowns of this equation, the backscatter and extinction coefficients, have to be related using either empirical or theoretical methods in order to be able to invert the lidar equation. There have been many discussions regarding the solutions of the lidar (e.g., Barrett and Ben-Dov, 1967; Viezee et al., 1969; Davis, 1969; Fernald, 1972; Platt, 1973, 1979; Klett, 1981; Fernald, 1984; Elouragini and Flamant, 1996, and Ansmann et al., 1992).

Forward solution of the backscatter coefficient was found to become rapidly unstable for optical depths greater than unity, unless the lidar ratio was specified with extreme accuracy (Platt, 1979). Klett (1981) showed that a backward solution of backscatter coefficient was inherently stable. However, Fernald (1984) further pointed out that stability does not necessarily mean accuracy. The backscatter coefficient and an effective lidar ratio can be retrieved, using both Klett and Fernald formalism, as proposed by Ansmann et al. (1992). This lidar ratio corresponds to the ratio of the cirrus optical depth to the backscatter coefficient integrated over the cirrus layers and can be interpreted as the cirrus-layer "mean" lidar ratio. We should also mention that until now we have not taken into account any multiple scattering correction and thus the above inversions lead to effective values of lidar ratio and optical depth.
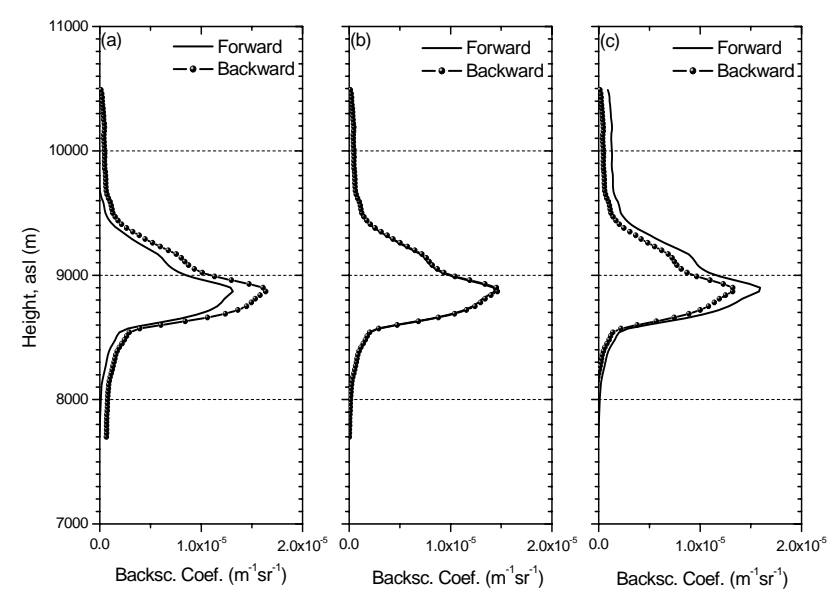

Fig. 1. Forward and backward solutions of lidar equation by assuming a range independent lidar ratio of (a) $10 \mathrm{sr}$, (b) $15 \mathrm{sr}$ and (c) $20 \mathrm{sr}$.

Once a priori altitudes of the base and the top of the cloud are chosen, we determine the effective lidar ratio that yields a zero backscatter coefficient above and below the cloud layer (Ansmann et al., 1992). Although the extinction coefficient profile can be incorrect because of the unrealistic assumption of a range-independent lidar ratio, the determined backscatter coefficient profile, the cloud optical depth, and the mean cloud extinction-to-backscatter ratio, can still be obtained with a high temporal resolution and an acceptable accuracy (Ansmann et al., 1992). In the case of a vertically pointing lidar, ice crystals oriented precisely horizontally cause a large backscatter signal due to specular reflection. Few oriented crystals are believed to be able to produce strongly enhanced backscattering and unrealistic low lidar ratios (Platt, 1978). Thus, the method in some of the measured cases may be influenced by the presence of the specular reflection effect.

During the application of Klett-Fernald, a gliding average filter with a window of $300 \mathrm{~m}$ was applied to smooth the range corrected signals. In the following, an example of the Klett-Fernald method is presented. At the 20 May 2006, a cirrus cloud was observed. The base of the cloud was detected at $7700 \mathrm{~m}$ while the top of the cloud was at $10500 \mathrm{~m}$. In Fig. 1 we present the backscatter coefficient profiles for three values of the effective lidar ratio $(10,15$ and $20 \mathrm{sr})$ and we can easily conclude that solution obtained for $L R=15 \mathrm{sr}$ leads to a zero backscatter coefficient above and below the cirrus cloud. At this value we can see that the forward and backward solutions tend to give the same backscatter profile. Thus the effective optical depth can then be obtained equal to 0.13 .

\subsubsection{Transmittance method}

In the second method, henceforth called the transmittance method, the effective optical depth of the cirrus cloud can be 


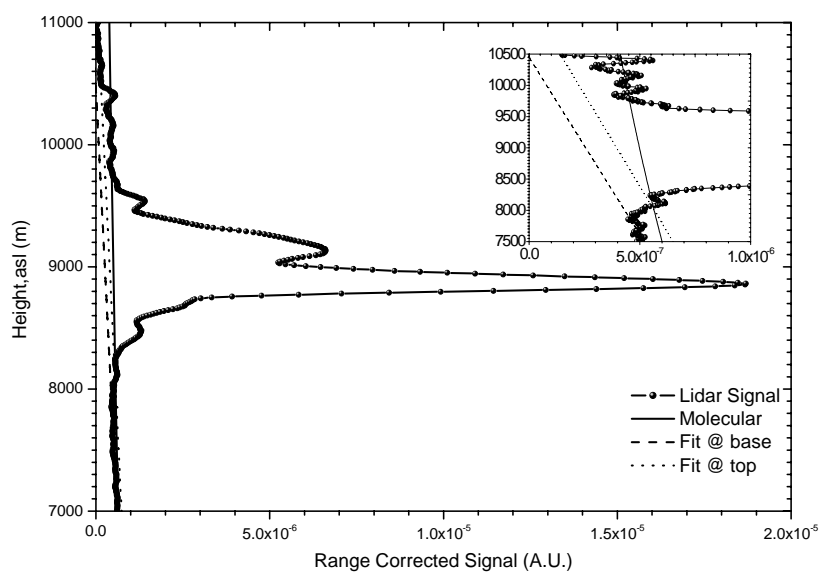

Fig. 2. Range corrected signal, along with molecular atmosphere and the applied fits outside of the cloud region.

determined by comparing the backscattering signals just below and above the cloud in the case whence lidar signals correctly represent the scattering medium (Platt, 1973; Young, 1995; Chen et al., 2002). A gliding average filter with a window of $300 \mathrm{~m}$ was applied in order to smooth the signals. Two linear fits of the scattering signals just below and above the cirrus cloud were applied. The transmission and effective optical depth of the cirrus cloud can then be obtained (Chen et al., 2002). From the calculated backscatter profile, as given by the Klett-Fernald method, we can thus estimate the effective lidar ratio.

In Fig. 2 we present the range-corrected lidar signal for the 20 May 2006. The black line corresponds to the simulated molecular profile which was calculated by the use of an air density profile obtained from a standard atmospheric model (U.S. Standard Atmosphere, 1976) adjusted to the measured ground-level temperature and pressure values, due to the absence of radiosonde measurement for this case study. The dashed and dotted lines are the corresponding linear fits of the lidar signal at the cloud base and cloud top, respectively. In this case study, the transmitance of the cloud is estimated to be 0.87 , and, the calculated (effective) optical depth is equal to 0.14 . This effective optical depth leads to the estimation of an effective lidar ratio equal to $17 \mathrm{sr}$, taking into account the backscatter profile as computed by the KlettFernald method.

\subsubsection{Raman method}

The Raman method is based on the measurement of the elastic-backscatter signal at $355 \mathrm{~nm}$ and of the nitrogen inelastic-backscatter signal at $387 \mathrm{~nm}$ which permits the independent determination of the extinction and backscatter coefficients thus provide the extinction-to-backscatter ratio (Ansmann et al., 1992). Raman lidar applications are limited to night time measurements since the weak inelastic
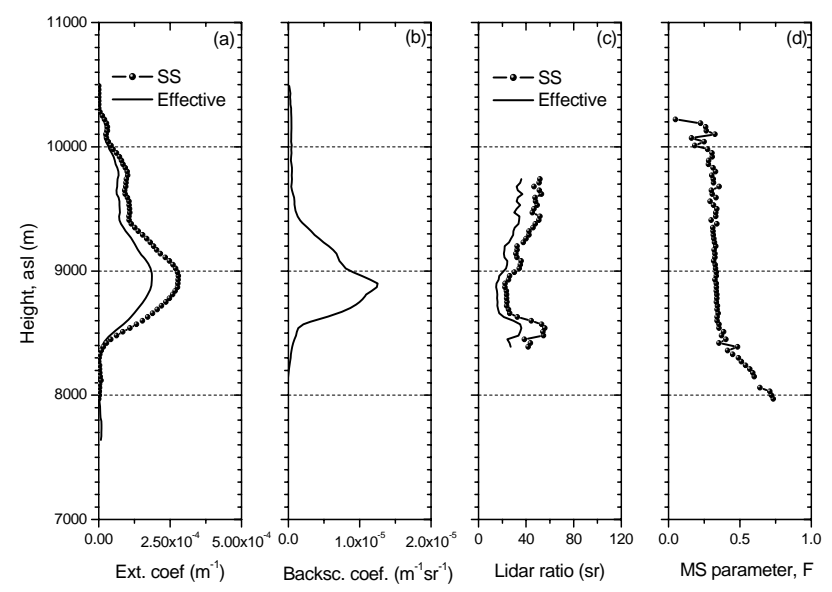

Fig. 3. Profiles of (a) extinction coefficient, (b) backscatter coefficient, (c) lidar ratio and (d) multiple scattering parameter, before and after the correction for multiple scattering effect.

backscatter signal can only be detected in the absence of the strong daylight background. For the final calculation of the extinction coefficient at $355 \mathrm{~nm}$, we calculate the derivative of the ratio between the atmospheric number density and the range-corrected lidar-received signal. For the calculation of the derivative a linear least square fit with a window of $600 \mathrm{~m}$ was applied to range corrected signals. In case of night-time measurements we also calculated the backscatter coefficient using both elastical and inelastic backscatter signals (Ansmann et al., 1992), after smoothing with a gliding window of $600 \mathrm{~m}$. For ice particles, which are usually large, compared to the laser wavelength, the wavelength dependence between the extinction at 355 and $387 \mathrm{~nm}$ is assumed negligible (Ansmann et al., 1992).

Figure 3 presents the calculated (effective) extinction (Fig. 3a) and backscatter (Fig. 3b) coefficients and the effective lidar ratio profile (Fig. 3c) for 20 May 2006 ("effective" optical properties implies calculations without taking into account multiple scattering corrections). The integration of the extinction coefficient leads to an effective optical depth of 0.17 , while mean effective lidar ratio is calculated as the average of effective lidar ratio and found to be equal to $26 \pm 7 \mathrm{sr}$. The difference on the lidar ratio that obtained by Raman and Klett-Fernald method is attributed not only to the assumption of a vertically constant lidar ratio for the solution of elastic differential equation but also to a possible effect of specular reflection in the $8.5-9 \mathrm{~km}$ altitude range. In addition Fig. 3 suggests lower values of lidar ratio in the region with strongest backscatter coefficient. Thus, the effective lidar ratio obtained by Klett-Fernald scheme is mainly influenced by the layer with larger backscatter coefficient. 


\subsection{Multiple scattering effect}

The transmittance of a light beam through a cloud is increased by multiple scattering effects, as photons scattered out of the sampling volume of the lidar in one scattering event may return to the lidar field of view in subsequent scattering events. Also, photons that are scattered at small forward angles are not lost from the lidar beam and may experience enhanced scattering (Young, 1995). Multiple scattering is significant in cirrus clouds and varies with cloud optical depth, cloud extinction and lidar penetration depth (Wang et al., 2005). As Wandinger (1998) showed, multiple-scattering errors of measured extinction coefficients are typically in the order of $50 \%$ at the bases of clouds and decrease with increasing penetration depth to below 20\%. Wang et al. (2005) showed that the presence of multiple scattering can lead to an underestimation of the extinction coefficient by as large as $200 \%$, whereas the backscattering coefficient is almost unaffected.

The retrieval of optical properties, as showed previously, leads to effective values of the optical depth and the lidar ratio. The receiver field of view of the LAP lidar is $1 \mathrm{mrad}$ and thus, the effective values are considerably influenced by multiple scattering. The approach to correct the estimated values of cirrus optical depth and lidar ratio depends on the applied method. For the transmittance method we assume a rangeindependent parameter. Following previous studies (Platt et al., 1987; Sassen and Cho, 1992; Chen et al., 2002), a factor $\eta$ is introduced, which describes the multiple scattering effect, henceforth called multiple scattering factor. According to Chen et al. (2002) the multiple scattering factor, for a cirrus cloud with an optical depth $\tau_{c}$, is calculated by Eq. (1).

$\eta=\frac{\tau_{c}}{\exp \left(\tau_{c}\right)-1}$

The smaller $\eta$ is, the more important the multiple scattering effect becomes. However, we should keep in mind that this approach is very simplified since we assume that multiple scattering factor is only depending on optical depth, not taking into account, the receiver field of view, the laser beam divergence and the size distribution and habit of the scatterers.

For the Raman and Klett-Fernald methods a different approach is used to address multiple scattering effects. The effective extinction coefficient $a_{\mathrm{eff}}(z)$, is related to the actual (single-scattering) coefficient $a(z)$ through a parameter $F(z)$ (here called multiple scattering parameter), as Eq. (2) shows (Wandinger, 1998; Wang, 2005).

$a_{\mathrm{eff}}(z)=(1-F(z)) * a(z)$

We should notice here that the ratio of the effective optical depth to the actual optical depth corresponds to the multiple scattering factor and thus, to the average value of $(1-F(z))$.
Multiple scattering parameter, $F(z)$ can be estimated through Eq. (3) (Wang et al., 2005), when the ratio of total signal $P_{\text {tot }}(z)$, to single-scattering signal $P_{1}(z)$ is known:

$F(z)=\frac{\frac{d}{d z} \ln \frac{P_{\mathrm{tot}}(z)}{P_{1}(z)}}{2 a_{\mathrm{eff}}(z)+\frac{d}{d z} \ln \frac{P_{\mathrm{tot}}(z)}{P_{1}(z)}}$

A radiative transfer model, provided by Hogan (2006), has been applied to estimate the relative contribution due to individual orders of multiple scattering. This model approximates the intensity of multiply scattering returns by dividing the outgoing photons into three populations: photons that have experienced zero, one and more than one forwardscattering event. Each of this population is parameterized in the model. This model has been compared to Eloranta's model (Eloranta, 1998) for a wide range of cloud profiles and lidar parameters and found that reproduces the high-order Eloranta calculation when the latter takes into account 5th or 6th order scattering (Hogan, 2006). This model was also used by Seifert et al. (2007) to estimate the contribution of multiple scattering effects to the effective optical properties of cirrus clouds during Indian Ocean Experiment (INDOEX).

A laser beam of $0.5 \mathrm{mrad}$ full-angle divergence with a wavelength of $355 \mathrm{~nm}$, and a receiver field of view of $1 \mathrm{mrad}$ are used in the model simulation. An issue in this simulation is the unknown size of the scatterers in the cloud. The model used implies hexagonal ice crystals. To estimate an approximate value of effective radius, which is needed as input for the model, we use the values given by Wang and Sassen (2002), who had related the effective radius with cirrus cloud temperature. The effective radius decreased from $70 \mu \mathrm{m}$ at $-30^{\circ} \mathrm{C}$ to $35 \mu \mathrm{m}$ at $-70^{\circ} \mathrm{C}$. The model also requires the single scattering extinction profile and the lidar ratio to estimate the total attenuated backscatter which is the backscatter influenced both by attenuation and multiple scattering effect. The model can also extract six individuals backscatter components (single, double and triple order of scattering for cloud and molecular atmosphere). However, the measurement provides as an output either the effective (total) value of extinction coefficient (Raman method) or the effective value of backscatter coefficient (Klett-Fernald). For this reason, as a first input we use the effective value of extinction for the Raman method and the effective backscatter coefficient profile multiplied by a constant lidar ratio for the Klett-Fernand method. From the computed ratio of the total attenuated backscatter profile to single attenuated backscatter coefficient we can make a first estimation of the multiple scattering parameter $F(z)$, as described in the studies of Wandinger (1998) and Wang et al. (2002). Then, a first estimation of the single-scattering extinction profile can be retrieved. A second or third iteration step is applied in order to estimate the parameter $F(z)$ and thus, the correct single scattering extinction profile.

The contribution of multiple scattering effects to the optical properties of the cirrus cloud for the case study of 20 May, 


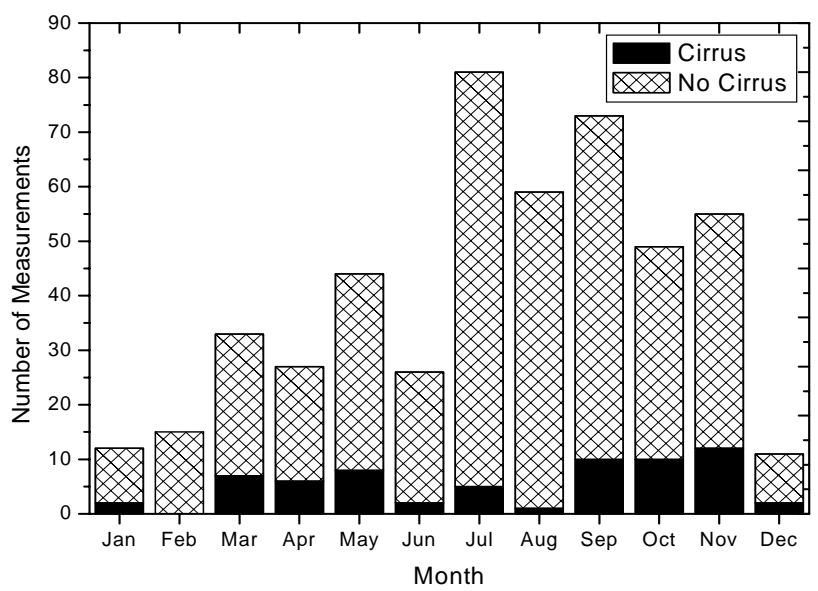

Fig. 4. Histogram of the number of cirrus occurrences and the total number of lidar measurements from 2000 to 2006 as a function of month.

2006 and for the Raman method is presented in Fig. 3 (solid lines with circles). The multiple scattering parameter $F(z)$ is decreasing with penetration height, as shown in Fig. 3d. This means that the multiple scattering error of the effective extinction coefficients decreases with increasing penetration depth. The profile averaged multiple scattering parameter $F$, for the Klett-Fernald and Raman methods, are 0.33 and 0.36 , respectively. The difference between these parameters is small and is justified by the fact that in the Klett-Fernald method we introduce as input the backscatter coefficient profile multiplied by the corresponding constant effective lidar ratio, while in the Raman method we import as input the extinction coefficient profile. For the Klett-Fernald method the resulting optical depth will be 0.18 and the lidar ratio will be $22 \mathrm{sr}$. For the Raman method these values are 0.25 and $34 \mathrm{sr}$, respectively. However, the multiple scattering factor $\eta$, which is calculated for the transmittance method and corresponds to the profile averaged value of $(1-F(z))$, is equal to 0.93 , much greater than the profile averaged model estimated values of $(1-F(z))$ which are equal to 0.67 and 0.64 , for the Klett-Fernald and Raman methods, respectively. Thus, for the transmittance method, multiple scattering effects will introduce a small change to the effective optical depth and lidar ratio, calculated to 0.15 and $18 \mathrm{sr}$ respectively. The difference between the approaches of multiple scattering effect are discussed in Sect. 4.2.

\section{Results and discussion}

During the period 2000-2006, 53 measurements of cirrus clouds were performed, 15 of them were night-time measurements and 38 were day-time measurements. In Fig. 4 a histogram of the number of cirrus occurrence (black) and the total number of measurements as a function of month is presented. Cirrus clouds are more frequently observed in
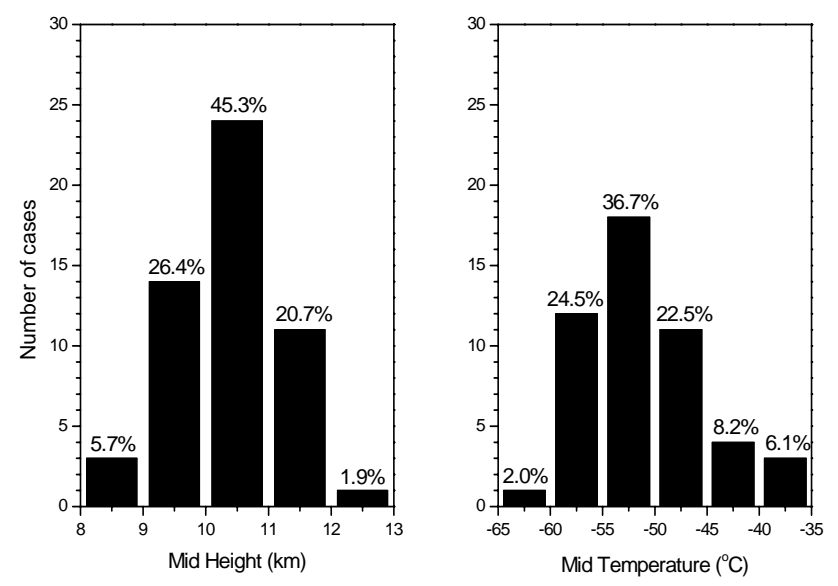

Fig. 5. Histogram of mid cloud height and mid cloud temperature of cirrus clouds.

autumn and spring than in summer. During winter-time the presence of low-level clouds inhibiting the laser to reach possible cirrus clouds and this is the reason for low frequency of lidar measurements. For that reason, the frequency occurrence will not be representative, and is not presented here.

\subsection{Geometrical and temperature characteristics}

As other studies have shown (Heymsfield and Platt, 1984; Platt and Harshvardhan, 1988; Sassen and Comstock, 2001; Wang and Sassen, 2002), temperature is an important factor in determing cirrus cloud properties. Platt et al. (1987), Mace et al. (2001), and Sassen and Comstock (2001) have also shown that cloud thickness is another significant factor that influences cirrus optical properties. All temperatures are obtained from radiosondes, launched at the Thessaloniki airport, twice per day, at 00:00 UTC and 12:00 UTC. The lidar measurement is within 2 hours from radiosonde launched while LAP lidar is approximately $10 \mathrm{~km}$ from Thessaloniki's airport. The boundaries of the cloud were determined as presented in the methodology section.

Histograms of mid cloud height and mid-cloud temperature are presented in Fig. 5. Cirrus clouds are generally observed in the mid-altitude region from 8.6 to $13 \mathrm{~km}$, with mid-cloud temperatures ranging from $-65^{\circ}$ to $-38^{\circ} \mathrm{C}$. The cloud thickness is generally in the range from 1 to $5 \mathrm{~km}$, with $38 \%$ of our cases have thickness between 2 and $3 \mathrm{~km}$. Almost half of our cases $(45.3 \%)$ have mid-cloud height in the range of 10 to $11 \mathrm{~km}$, while mid-cloud temperature centered around $-52.5^{\circ} \mathrm{C}$. Wider ranges of mid-heights and mid-temperature distributions were reported by Reichardt et al. (1998). However, almost $50 \%$ of those data were found in ranges between 9 and $11 \mathrm{~km}$ for the mid-heights and from -50 to $-60^{\circ} \mathrm{C}$ for mid-cloud temperatures. Since this mid-latitude cirrus dataset lies in the same height and temperature ranges with our measurements, it is appropriate for direct comparison. 
Table 1. Seasonal and yearly averages of various cirrus cloud properties.

\begin{tabular}{lrrr}
\hline Cirrus Properties & Cold & Warm & Annual \\
\hline Base height $(\mathrm{km})$ & $8.6 \pm 1.0$ & $9.2 \pm 1.1$ & $9.0 \pm 1.1$ \\
Mid height $(\mathrm{km})$ & $10.0 \pm 0.8$ & $10.5 \pm 0.9$ & $10.3 \pm 0.9$ \\
Top height $(\mathrm{km})$ & $11.6 \pm 0.9$ & $11.8 \pm 1.0$ & $11.7 \pm 0.9$ \\
Thickness $(\mathrm{km})$ & $3.0 \pm 1.0$ & $2.6 \pm 0.8$ & $2.7 \pm 0.9$ \\
Base temperature $\left({ }^{\circ} \mathrm{C}\right)$ & $-36.7 \pm 7.8$ & $-41.1 \pm 7.8$ & $-40.6 \pm 7.9$ \\
Mid temperature $\left({ }^{\circ} \mathrm{C}\right)$ & $-51.2 \pm 5.3$ & $-51.0 \pm 6.1$ & $-51.1 \pm 5.5$ \\
Top temperature $\left({ }^{\circ} \mathrm{C}\right)$ & $-61.3 \pm 5.9$ & $-59.5 \pm 5.1$ & $-60.2 \pm 5.4$ \\
\hline
\end{tabular}

To further investigate the variability of geometrical and temperature characteristics during the year we have separate our data into two periods. The "cold period" is regarded to be from November to March (18 cases), while the "warm period" is from April to October (35 cases). In Table 1 we present the average value as well as the variability in several geometrical and temperature characteristics of cirrus clouds for each period and for the whole year, concerning Thessaloniki dataset for the period from 2000 to 2006 . The average base of cirrus clouds tends to be lower during the cold period, while the top of cirrus clouds varies less during the year. The mean mid height of cirrus clouds appears $0.5 \mathrm{~km}$ higher during the warm period. The mean thickness of cirrus clouds is $2.7 \pm 0.9 \mathrm{~km}$ and is little thinner during the warm period of the year. These small variations between the warm and cold period are reflected in the temperature values as well.

\subsection{Optical properties of cirrus clouds}

We have applied the methods which were briefly presented in the methodology section to all the lidar measurements containing signals from cirrus clouds. The Klett-Fernald method gave reliable results for 42 of the cloud cases, while the transmittance method gave reliable results for 32 of the cases. The reasons why these methods do not give reliable results in certain cases is discussed in the next paragraph. Figure 6 shows the direct comparison of the optical depth at $355 \mathrm{~nm}$ as derived from the three methods, after taking into account multiple scattering effects. The two sets of independently derived optical depth are in good agreement, with a correlation coefficient of 0.82 for the Transmittance/Klett-Fernald comparison and of 0.90 for the Raman/Klett-Fernald comparison.

The reason that Klett-Fernald method cannot give a reliable result in all of our cases is the numerical instability that appears at very low optical depths. In cases when the cirrus cloud is optically thin, this method is not sensitive to changes in the lidar ratio values and thus, lidar ratio cannot be uniquely defined. The disagreement between the KlettFernald and Raman methods exists in some cases is due to the assumption of a vertically constant lidar ratio for the solution of elastic differential equation. In these cases we have found that lidar ratios derived from the Klett-Fernald method

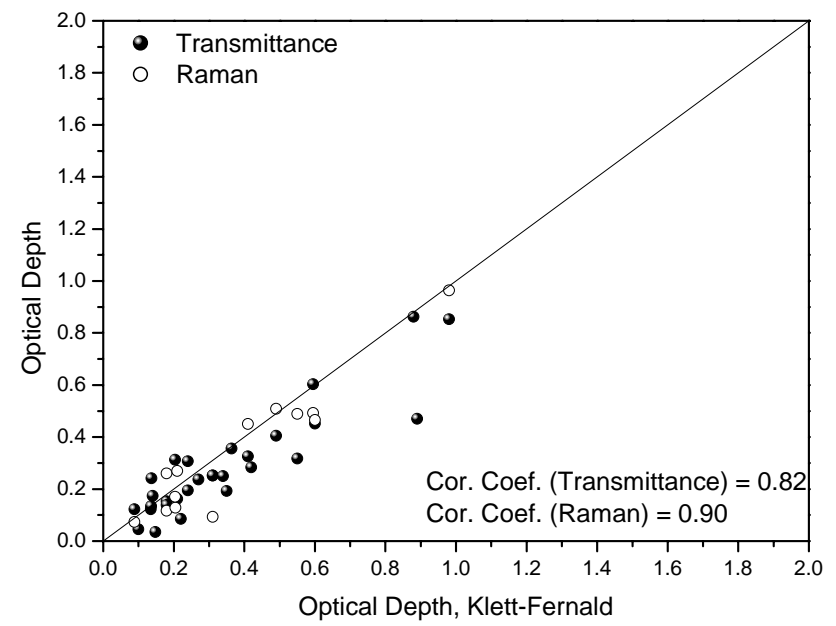

Fig. 6. Comparison of cirrus optical depth of Klett-Fernald method with Transmitance and Raman methods.

tend to agree with the lidar ratio of the lowest layer of the cirrus cloud. The backscatter coefficients as calculated by the Klett-Fernald and Raman methods retrieve the same results for measured cirrus clouds structure. This means that the two methods give reliable profiles of backscatter coefficients. In the transmittance method, as we have already mentioned, the divergence of the signal between the bottom and top of the cloud can procure the real transmittance of the cloud and thus the optical depth. In cases when the signal is too noisy at the top of the cloud, or there are some lower layers that cannot be distinguished, the applying fit can lead to erroneous values of the optical depth and the lidar ratio because of uncertainties in determining accurately the cloud physical thickness.

For 13 cases, analyses based on the Klett-Fernald, transmittance and Raman methods yield mean optical depths of $0.38 \pm 0.25,0.34 \pm 0.22$ and $0.34 \pm 0.25$, respectively. Lidar ratios values were determined as $31 \pm 17,28 \pm 18$ and $34 \pm 18$ sr, respectively. For 29 cases, application of KlettFernald and transmittance methods, yield mean optical depths values of $0.35 \pm 0.24$ and $0.29 \pm 0.20$, and, lidar ratio of $31 \pm 14$ and $25 \pm 14 \mathrm{sr}$, respectively. The calculated values for both optical depth and lidar ratio are generally in good agreement, especially if one considers i) that the transmittance method uses only the elastic signal while Klett-Fernald formalism use the assumption of a range-independent lidar ratio for solving the single scattering lidar equation, and, ii) the Raman method uses both elastic and inelastic backscatter signals.

To further investigate the distribution of optical depth, we present a histogram of cirrus cloud optical depth in Fig. 7. The most prevalent region of cirrus optical depth values is between 0.2 and 0.3 . We have found that only $3 \%$ of cirrus clouds are sub-visual (optical depth $<0.03$ ), $57 \%$ of cirrus clouds are optically thin (optical depth between 0.03 and 0.3 ) and $40 \%$ of cirrus clouds are opaque (optical depth $>0.3$ ). 
Table 2. Mean optical properties of cirrus clouds for each method before and after correction for multiple scattering.

\begin{tabular}{lccccc}
\hline Method & No. of cases & Effective Optical Depth & Optical Depth & Effective Lidar ratio (sr) & Lidar ratio (sr) \\
\hline Klett-Fernald & 42 & $0.19 \pm 0.17$ & $0.31 \pm 0.24$ & $18 \pm 12$ & $30 \pm 17$ \\
Transmittance & 31 & $0.29 \pm 0.26$ & $0.34 \pm 0.32$ & $23 \pm 20$ & $29 \pm 24$ \\
Raman & 15 & $0.23 \pm 0.19$ & $0.33 \pm 0.25$ & $25 \pm 13$ & $36 \pm 20$ \\
\hline
\end{tabular}

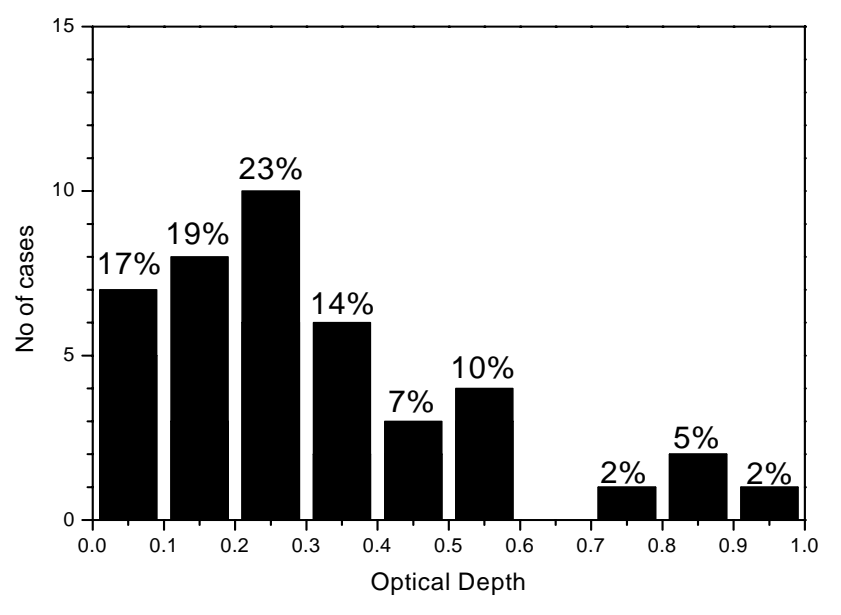

Fig. 7. Histogram of cirrus optical depth.

Sassen and Campbell (2001) had found that cirrus clouds optical depths were below 0.3 for $50 \%$ of the cases included into their mid-latitude station cirrus climatology analysis, while Reichardt (1998) found that cirrus clouds have optical depth lower than 0.3 for $70 \%$ of the cases studied. Our results show that $60 \%$ of the cirrus clouds are subvisual or optically thin (that means optical depth $<0.3$ ).

In Table 2, we present the mean values of the optical depth and the lidar ratio, as were calculated for all of our cases, before (effective) and after correction for multiple scattering effects. The values which are presented in Table 2 are not directly comparable, as they are not referring to the same cases of cirrus clouds. We note that the mean optical depth, as derived from the transmittance method, is high because of the instability associated with its determination for cirrus clouds with low optical depths (discussed in Sect. 4.2). Also, we should mention that the specular reflection effect has probably been observed in some of the measured cirrus clouds cases. In $20 \%$ of the total cases where Klett-Fernald method was applied, the results showed an unrealistic effective lidar ratio of $5 \mathrm{sr}$. This may be attributed to the specular reflection and thus can introduce a strong bias towards smaller lidar ratios. This is possible the reason that the average values of the effective and multiple scattering corrected lidar ratios, estimated by Klett-Fernald method, are lower than the average ones calculated by Raman method, as it is demonstrated in Table 2.
The values presented in Table 2 may be compared with other climatological studies. Sassen and Comstock (2001) had studied mid-latitude cirrus clouds, using an extended database, and found mean optical depths of $0.75 \pm 0.91$ at $694 \mathrm{~nm}$, while the lidar ratio was found equal to $24 \mathrm{sr}$. Wang and Sassen (2002), had also studied mid-latitude cirrus clouds, for the period 1996-2000, and found that most of the cirrus clouds were optically thin, with a mean effective optical depth of $0.58 \pm 0.67$. Cirrus climatological results from Observatoire de haute Provence in France are presented by Goldfarb et al. (2001) and suggest as more prevalent optical depth in the region from 0.03 to 0.1 . In addition, Seifert et al. (2007) have studied the optical properties of cirrus clouds over the tropical Indian ocean during Northeast (NE) and Southwest (SW) monsoon seasons. They found a multiple-scattering corrected optical depth of $0.25 \pm 0.26$ (NE) and $0.34 \pm 0.29(\mathrm{SW})$, while the lidar ratio values were found to be $33 \pm 9 \mathrm{sr}(\mathrm{NE})$ and $29 \pm 11 \mathrm{sr}(\mathrm{SW})$.

We can further compare the contribution of multiple scattering effects as calculated for the different methods. The range-independent parameter $\eta$ that is used in the transmittance method has a mean value of $0.86 \pm 0.1$. However, the corresponding profile averaged parameter $(1-F(z))$, which is used in the Klett-Fernald and Raman methods, is smaller and mostly ranges from 0.6 to 0.75 . This means that the contribution of multiple scattering effects as applied in the transmittance method is smaller than the calculated contribution to the Klett-Fernald and Raman methods, especially for optically thin clouds. These differences in the multiple scattering correction between the two approaches were found also in the rest of the cases. Some typical values of multiple scattering factor $\eta$, as given by Chen et al. (2002) are: $\eta=0.58$ for $\tau_{c}=1$ and $\eta=0.95$ for $\tau_{c}=0.1$. Sassen and Comstock (2001) assume that multiple scattering factor is of 0.9 for subvisual cirrus clouds, of 0.8 for relatively thick clouds and of 0.6 to 0.7 for optically thick clouds. However, these assumptions are in contradiction to the model results. Multiple scattering simulations show an increase of the multiple scattering factor with optical depth. The values of the multiple scattering factor is approximately 0.6 for optical depths lower than 0.1 , while for optical thicker clouds this factor ranges from 0.6 to 0.8 . Thus, we should mention that the approach for dealing with cirrus clouds and multiple scattering contribution, when the transmittance method is used, is very simplified and can lead to unrealistic estimates for thin cirrus clouds. 
However, when transmittance method is used, neither the extinction coefficient nor the backscatter coefficient profiles are available in order to use model simulations. We have also found that the multiple scattering parameter $F(z)$ is decreasing with penetration height. This means that multiple scattering errors of measured extinction coefficients decrease with increasing penetration depth. Similar results were reported by Wandinger (1998). Assuming that the backscatter coefficient is almost unaffected from multiple scattering, lidar ratio errors are affected only by the extinction coefficient errors.

\subsection{Temperature and thickness dependencies on cirrus op-} tical properties

The dependence of optical depth on cirrus cloud thickness is shown in Fig. 8. In order to investigate this dependence we have grouped cirrus clouds cases into $0.5 \mathrm{~km}$ intervals. We should mention that cirrus cases analysis that refer to thickness lower than $1.5 \mathrm{~km}$ are of low significance. There is an indication that optical depth increases with increasing thickness. To the top of Fig. 8 a histogram showing the absolute number of cirrus clouds occurrence per thickness interval is presented, while the per cent are also mentioned. Sassen and Comstock (2001) showed that these parameters follow a linear relation. For comparison, the relation found at the ICE'89 campaign (Ansmann et al., 1993) is also plotted in the same figure (dashed line). The correlation found to the ICE' 89 campaign is higher than the one for our study. This may attributed to the different distributions in mid-cloud temperatures because warm clouds tend to have higher optical depths. However, the correlation that was found in this study seems to be in a good agreement with the corresponding correlation found by Reichardt (1998), since the two datasets are lying in the same height and temperature ranges. Although not shown here, we have also studied the dependence of lidar ratio on cloud thickness and no clear tendency was found.

The dependence of cirrus cloud thickness on mid-cloud temperature is presented in Fig. 9a. Thicker clouds $(\sim 3.5 \mathrm{~km})$ are observed at temperatures of $\sim-47.5^{\circ} \mathrm{C}$, decreasing in thickness both for higher and lower temperatures. Platt et al. (1987), showed a well defined peak at higher temperatures around $-40^{\circ} \mathrm{C}$ for mid-latitude clouds. Our results are in agreement with Sassen and Comstock (2001) who have also presented the dependence of cloud thickness on mid-cloud temperature. Sunilkumar and Parameswaran (2005) studied tropical cirrus clouds and found that this peak is shifted to lower temperatures, in the range of $-50^{\circ}$ to $-70^{\circ} \mathrm{C}$. The conclusion of Sunilkumar and Parameswaran (2005) that mid-latitude cirrus clouds are generally warmer and thicker than those over the tropics is in agreement with our results. However, we should keep in mind that the number of samples corresponding to temperatures below $-60^{\circ} \mathrm{C}$ is limited. Furthermore, the dependence of the optical depth on cirrus thickness is shown in Fig. 9b while the dependence of the mean extinction coefficient on mid-cloud temperature

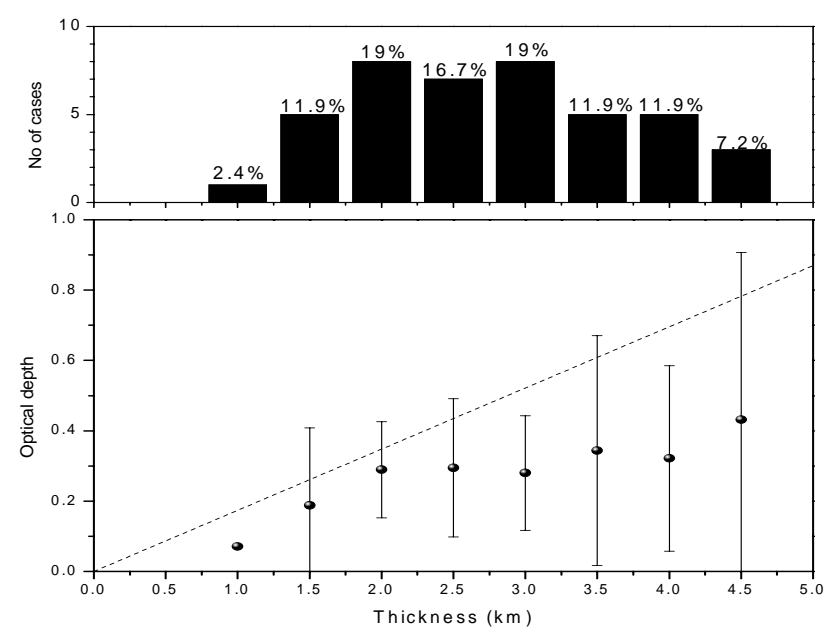

Fig. 8. Dependence of optical depth on $0.5 \mathrm{~km}$ intervals of thickness. The dashed line represents the regression line given by Ansmann et al. (1993). At the top, the histogram of cirrus clouds occurrence observed per thickness interval is presented. No error bar means that the result is based only on a single measurement.

is presented in Fig. 9c. For the remaining data shown in Fig. $9 \mathrm{~b}$ there are indications that the cloud optical depth increases as the mid-cloud temperature increases. Other studies have also investigated the dependence of optical depth on mid-cloud temperature and found that these parameters are connected either linearly (Sassen and Comstock, 2001) or through a second-order polynomial function (Sunilkumar and Parameswaran, 2005; Platt et al., 1987). Finally, the dependence of the ratio of optical depth to thickness (mean extinction coefficient) as a function of mid-cloud temperature is examined. Excluding the point of temperature below $-60^{\circ} \mathrm{C}$ (which is of low statistical significance since it is referring to only one measurement), we found that the mean extinction coefficient decreases with mid-cloud temperature. The results of Fig. 9 are in agreement with those of Reichardt (1998) both concerning the pattern and the absolute values. However these results are indicative only and more cases should be collected to our database for a more accurate conclusion. Although not shown here, we have also studied the dependence of lidar ratio on mid-cloud temperature and no clear tendency was found.

\section{Summary and conclusions}

This study provides an analysis of the geometrical and temperature characteristics as well as the optical properties of mid-latitude cirrus clouds. Our results show that cirrus clouds were observed between 8.6 to $13 \mathrm{~km}$, with mid-cloud temperatures ranging from $-65^{\circ}$ to $-38^{\circ} \mathrm{C}$ and a mean thickness of $2.7 \pm 0.9 \mathrm{~km}$. We have also provided the optical properties of mid-latitude cirrus clouds as were calculated 

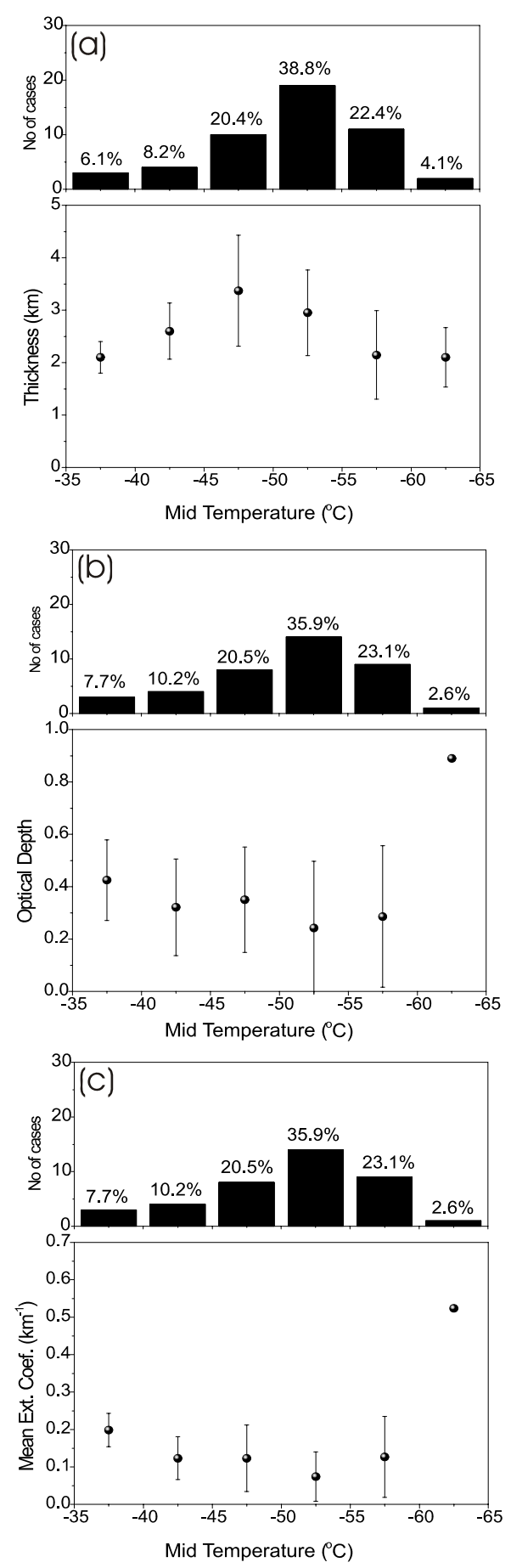

Fig. 9. Depedencies of (a) thickness (b) optical depth and (c) mean extinction coefficient on $5^{\circ} \mathrm{C}$ intervals of mid cloud temperature. At the top of each figure, histograms of cirrus clouds occurrence per mid-temperature interval are presented. No error bar means that the result is based only on a single measurement.

through three different methods. A mean optical depth of $0.31 \pm 0.24$ and a mean lidar ratio of $30 \pm 17 \mathrm{sr}$ were found following the scheme of Klett-Fernald formalism. Sub-visual cirrus clouds represent $12 \%$ of our measurements before the correction for multiple scattering while this percentage is reduced to $3 \%$, after the correction. In addition, we have compared the resulting optical depth and lidar ratio and found a good agreement between the three methods applied. The comparison has been performed to the single-scattering values of the optical depths and correlation coefficients of 0.82 and 0.90 were found for the Transmittance/Klett-Fernlad method and the Raman/Klett-Fernlad method respectively. In the following we report briefly the benefits and restrictions of each method.

The main advantage of the Transmittance method is that it does not require any microphysical hypotheses about cirrus clouds. However, this method depends on the condition of the atmosphere outside the cloud because the presence of aerosol particles can affect the lidar signals significantly due to Rayleigh scattering effects. Another limitation of this method is that optically thin cirrus clouds have too low optical depth to produce rapid enough convergence for the solution. In that case there are more uncertainties related with the errors in the estimation of the boundary height or for noise or offset calculations of the lidar signal at the calibration range, as also Young (1995) have presented. On the other hand, the Klett-Fernald method uses a strong elastic-backscatter signal that is several orders of magnitude larger than the Raman signal in order to retrieve the backscatter coefficient. This is considered as a main benefit of this method. However, to solve the lidar equation through the Klett-Fernald formalism we assume a range independent lidar ratio. The accurate estimation of the extinction coefficient is possible through the Raman lidar technique and thus makes this method a powerful tool for cirrus studies. The independent measurement of backscatter and extinction profiles and thus lidar ratio profiles is only possible through the Raman method. Nevertheless, this method can be applied only for night- time measurements.

We have also investigated the dependence of optical properties on temperature and geometrical characteristics. A maximum mid-cloud depth is in the range of $\sim 3.5 \mathrm{~km}$ at temperatures between $-45^{\circ} \mathrm{C}$ and $-50^{\circ} \mathrm{C}$, and decreases both for lower and larger temperatures. An indication that optical depth and mean extinction coefficient increases with increasing mid-cloud temperature is found, while a dependence of optical depth on the geometrical thickness of cirrus clouds was also found. Our results seem to demonstrate that mid-latitude cirrus clouds are warmer, lower and thicker than tropical cirrus clouds. However, a more extended database is needed to strengthen these indications.

Acknowledgements. E. Giannakaki acknowledges the support of the PENED 2003 project. The project is co-financed 75\% of public expenditure through EC - European Social Fund and 25\% of public expenditure through Ministry of Development, General Secretariat of Research and development and through private sector. Measurements were performed in the frame of the EU-funded EARLINET 
and EARLINET-ASOS projects (EVR1-CT1999-40003 and RICA 025991). Radiosonde data for Thessaloniki were kindly provided by the Hellenic National Meteorological Service. The authors would like to acknowledge the editor A. Nenes for his work on the substantial improvement of the manuscript both on scientific and language issues.

Edited by: A. Nenes

\section{References}

Amiridis, V., Balis, D. S., Kazadzis, S., Bais, A., Giannakaki, E., Papayannis, A., and Zerefos, C.: Four-year aerosol observation with a Raman lidar at Thessaloniki, Greece, in the framework of EARLINET, J. Geophys. Res., 110, D21203, doi:10.1029/2005JD006190, 2005.

Ansmann, A., Wandinger, U., Riebesell, M., Weitkamp, C., and Michaelis, W.: Independent measurement of extinction and backscatter profiles in cirrus clouds by using a combined Raman elastic backscatter lidar, Appl. Opt., 31, 7113-7131, 1992.

Ansmann, A., Bosenberg, J., Brogniez, G., Elouragini, S., Flamant, P., Klapheck, K., Linn, H., Menenger, L., Michaelis, W., Riebesell, M., Senff, C., Thro, P. Y., Wandinger, U., Weitkamp, C.: Lidar network observations of cirrus morphological and scattering properties during the international cirrus experiment 1989: The 18 October 1989 case study and statistical analysis, J. Appl. Meteorol., 32, 1608-1622, 1993.

Balis, D. S., Amiridis, V., Zerefos, C., Gerasopoulos, E., Andreae, M., Zanis, P., Kazantzidis, A., Kazadzis, S., and Papayannis, A.: Raman lidar and sunphotometric measurements of aerosol optical properties over Thessaloniki, Greece during a biomass burning episode, Atmos. Environ., 37, 4529-4538, 2003.

Barrett, E. W. and Ben-Dov, O.: Application of the lidar to air pollution measurements, J. Appl. Meteorol., 6, 500-515, 1967.

Bockmann, C., Wandinger, U., Ansmann, A., Bosenberg, J., Amiridis, V., Boselli, A., Delaval, A., De Tomasi, F., Frioud, M., Grigovov, I. V., Hagard, A., Iarlori, M., Komguem, L., Kreipl, S., Larcheveque, G., Matthias, V., Papayannis, A., Pappalardo, G., Rocadenbosch, F., Rodrigues, J. A., Schneider, J., Scherbakov, V., and Wieger, M.: Aerosol lidar intercomparison in the framework of the EARLINET project: 2. Aerosol backscatter algorithms, Appl. Opt., 43, 977-989, 2004.

Cadet, B., Goldfarb, L., Faduilhe, D., Baldy, D., Giraud, V., Keckhut, P., and Rechou, A.: A sub-tropical cirrus clouds climatology from Reunion island $\left(21^{\circ} \mathrm{S}, 55^{\circ} \mathrm{E}\right)$ lidar data set, Geophys. Res. Lett., 30(3), 1130, doi:10.1029/2002GL016342, 2003.

Chen, W. N., Chiang, C. W., and Nee, J. B.: Lidar ratio and depolarization ratio for cirrus clouds, Appl. Opt., 41, 6470-6476, 2002.

Comstock, J. M. and Ackerman, T.: Ground-based lidar and radar remote sensing of tropical cirrus clouds at Nauru island: Cloud statistics and radiative impacts, J. Geophys. Res., 107(23), 4714, doi:10.1029/2002JD002203, 2002.

Davis, P. A.: The analysis of lidar signatures of cirrus clouds, Appl. Opt., 8, 2099-2102, 1969.

Eloranta, E.: Practical model for the calculation of multiply scatterd lidar returns, Appl. Opt., 37, 2464-2474, 1998.

Elouragini, S. and Flamant, P. H.: Iterative method to determine an averaged backscatter-to-extinction ratio in cirrus clouds, Appl.
Opt., 35, 1512-1518, 1996.

Fahey, D. W. and Schumann, U.: Aviation-Produced Aerosols and Cloudiness, Chapters 3 in Aviation and Global Atmosphere, A Special Report of IPCC (Intergovernmental Panel on Climate Change), edited by: Penner, J. E., Griggs, D. H., Dokken, D. J., McFarland, M., Cambridge University Press, Cambridge, UK, 65-120, 1999.

Fernald, F. G., Herman, B. M., and Reagon, J. A.: Determination of aerosol height distributions by lidar, J. Appl. Meteorol., 11, 482-489, 1972.

Fernald, F. G.: Analysis of atmospheric lidar observations; some comments, Appl. Opt., 23, 652-653, 1984.

$\mathrm{Fu}$, Q. and Liou, K. N.: Parameterization of the Radiative Properties of Cirrus Clouds, J. Atmos. Sci., 50, 2008-2025, 1993.

Goldfarb, L., Keckhut, P., Chanin, M.-L., and Hauchecorne, A.: Cirrus climatological results from lidar measurements at OHP ( $\left.44^{\circ} \mathrm{N}, 6^{\circ} \mathrm{E}\right)$, Geophys. Res. Lett., 28, 1967-1690, 2001.

Grund, C. J and Eloranta, E. W.: The 27-28 October 1986 FIRE IFO Cirrus Case Study: Cloud Optical Properties Determined by High Spectral Resolution Lidar, Mon. Wea. Rev., 118, 23442355, 1990.

Heymsfield, A. J. and Platt, C. M. R.: A parameterization of the particle size spectrum of ice clouds in terms of the ambient temperature and the ice water content, J. Atmos. Sci., 41, 846-855, 1984.

Hogan, R.: Fast approximate calculation of multiply scattered lidar returns, Appl. Opt., 45, 5984-5992, 2006.

Intergovernmental Panel on Climate Change, in Climate Change 2007: The Physical Science Basis. Contribution of Working Group I to the Fourth Assessment Report of the Intergovernmental Panel on Climate Change, Cambridge University Press, Cambridge, United Kingdom and New York, NY, USA, 2007.

Klett, J. D.: Stable analytical inversion solution for processing lidar returns, Appl. Opt., 20, 211-220, 1981.

Lynch, D.: Cirrus history and definition, in: Cirrus, edited by: Lynch, D. K., Sassen, K., Starr, D. O., and Stephens, G. L., 3, Oxford University Press, 2002.

Mace, G. G., Clothiaux, E. E., and Ackerman, T. P.: The composite characteristics of cirrus clouds: Bulk properties revealed by one year continues cloud radar data, J. Climate, 14, 2185-2203, 2001.

Matthias, V., Bosenberg, J., Freudenthaler, V., Amodeo, A., Balin, I., and Balis, D.: Aerosol lidar intercomparison in the framework of EARLINET project: 1. Instruments, Appl. Opt., 43, 961-976, 2004.

Pappalardo, G., Almodeo, A., Pandolfi, M., Wandinger, U., Ansmann, A., Bosenberg, J., Matthias, V., Amiridis, V., De Tomasi, F., Frioud, M., Iarlori, M., Komguem, L., Papayannis, A., Rocadenbosch F., and Wang, X.: Aerosol intercomparison in the framework of EARLINET project: 3. Raman lidar algorithm for aerosol extinction, backscatter, and lidar ratio, Appl. Opt., 43, 5370-5385, 2004.

Platt, C. M. R.: Lidar and radiometric observations of cirrus clouds, J. Atmos. Sci., 30, 1191-1204, 1973.

Platt, C. M. R.: Lidar backscatter from horizontal ice crystal plates, J. Appl. Meteorol, 17, 482-488, 1978.

Platt, C. M. R.: Remote sounding of high clouds. I: Of visible and infrared optical properties from lidar and radiometer measurements, J. Appl. Meteorol., 18, 1130-1143, 1979. 
Platt, C. M. R., Scott, J. C., and Dilley, C.: Remote sounding of high clouds.Part VI: Optical properties, J. Atmos. Sci., 44, 729-747, 1987.

Platt, C. M. R. and Harshvardhan: Temperature dependencies of cirrus extinction: implications for climate feedback, J. Geophys. Res., 93, 11 051-11 058, 1988.

Platt, C. M. R., Young, S. A., Carswell, A. I., Pal, S. R., McCormick, M. P., Winker, D. M., DelGuasta, M., Stefanutti, L., Eberhard, W. L., Hardesty, M., Flamant, P. H., Valentin, R., Forgan, B., Gimmestad, G. G., Jager, H., Khmelevtsov, S., Kovel, I., Kaprieolev, B., Lu, Da-ren, Sassen, K., Shamanaev, V. S., Uchino, O., Mizuno, Y., Wandinger, U., Weitkamp, C., Ansmann, A., and Wooldridge, C.: The experimental cloud lidar pilot study (ECLIPS) for cloud-radiation research, B. Am. Meteorol. Soc., 75, 1635-1654, 1994.

Reichardt, J.: Optical and Geometrical Properties of Northern Midlatitude Cirrus Clouds Observed with a UV Raman lidar, Phys. Chem. Earth (B), 24, 255-260, 1999.

Sassen, K. and Cho, B.Y.: Subvisual-thin cirrus lidar dataset for satellite verification and climatological research, J. Appl. Meterorol., 31, 1275-1285, 1992.

Sassen, K. and Campbell, J. R.: A midlatitude cirrus cloud climatology from the facility for atmospheric remote sensing, part I: Macrophysical and synoptic properties, J. Atmos. Sci., 58, 481496, 2001.

Sassen K. and Comstock, J.: A midlatitude cirrus cloud climatology from the facility for atmospheric remote sensing. Part III: Radiative properties, J. Atmos. Sci., 58, 2113-2127, 2001.

Seifert, P., Ansmann, A., Muller, D., Wandinger, U., Althausen, D., Heymsfield, A. J., Massie, S. T., and Schmitt C.: Cirrus optical properties observed with lidar, radiosonde, and satellite over the tropical Indian Ocean during the aerosol-polluted northeast and clean maritime southwest monsoon, J. Geophys. Res., 112, D17205, doi:10.1029/2006JD008352, 2007.
Stephens, G. L. and Webster, P.J.: Clouds and Climate: Sensitivity of Simple Systems, J. Atmos. Sci., 38, 235-247, 1981.

Sunilkumar, S. V. and Parameswaran, K.: Temperature dependence of tropical cirrus properties and radiative effects, J. Geophys. Res., 110, D13205, doi:10.1029/2004JD005426, 2005.

Viezee, W., Uthe, E. E., and Collis, R. T. H.: Lidar observations of airfield approach conditions, J. Appl. Meteorol., 8, 274-283, 1969.

Wandinger, U.: Multiple-scattering influence on extinction-and backscatter-coefficient measurements with Raman and highspectral-resolution lidars, Appl. Opt., 37, 417-427, 1998.

Wang, P., Minnis, P. McCormick, M. P., Kent, G. S., and Skeens, K. M.: A 6-year climatology of cloud occurrences frequency from Stratospheric Aerosol and Gas Experiment II observations (1985-1990), J. Geophys. Res., 101, 29 407-29 429, 1996.

Wang, P., Minnis, P., McCormick, M. P., Kent, G. S., Yue, G. K., Young, D. F., and Skeens, K. M.: A study of the vertical structure of tropical $\left(20^{\circ} \mathrm{S}-20^{\circ} \mathrm{N}\right)$ optically thin clouds from SAGE II observations, Atmos. Res., 47-48, 599-614, 1998.

Wang, Z. and Sassen, K.: Cirrus cloud microphysical property retrieval using lidar and radar measurements. Part II: Midlatitude cirrus microphysical and radiative properties, J. Atmos. Sci., 59, 2291-2302, 2002.

Wang, X., Boselli, A., Avino, L. D., Velotta, R., Spinelli, N., Bruscaglioni, P., Ismaelli, A., and Zaccanti, G.: An algorithm to determine cirrus properties from analysis of multiple-scattering influence on lidar signals, Appl. Phys. B, 80, 609-615, 2005.

Young, S.: Analysis of lidar backscatter profiles in optically thin cirrus, Appl. Opt., 34, 7019-7031, 1995.

Zerefos, C. S., Eleftheratos, K., Balis, D. S., Zanis, P., Tselioudis, G., and Meleti, C.: Evidence of impact of aviation on cirrus cloud formation, Atmos. Chem. Phys., 3, 1633-1644, 2003, http://www.atmos-chem-phys.net/3/1633/2003/. 